\title{
Isolated metastasis of an EGFR-L858R-mutated NSCLC of the meninges: the potential impact of CXCL12/CXCR4 axis in EGFR NSCLC in diagnosis, follow-up and treatment
}

Florian Lüke ${ }^{1}$, Raquel Blazquez ${ }^{1}$, Rezan Fahrioglu Yamaci ${ }^{2}$, Xin Lu $^{2}$, Benedikt Pregler $^{3}$, Stefan Hannus ${ }^{4}$, Karin Menhart ${ }^{5}$, Dirk Hellwig5, Hans-Jürgen Wester ${ }^{6}$, Saskia Kropf ${ }^{7}$, Daniel Heudobler ${ }^{1}$, Jirka Grosse ${ }^{5}$, Jutta Moosbauer ${ }^{5}$, Markus Hutterer ${ }^{8,9,10}$, Peter Hau ${ }^{8,9}$, Markus J. Riemenschneider ${ }^{11}$, Michaela Bayerlová ${ }^{12}$, Annalen Bleckmann ${ }^{12,13}$, Bernhard Polzer ${ }^{14}$, Tim Beißbarth ${ }^{12}$, Christoph A. Klein ${ }^{2,14}$ and Tobias Pukrop ${ }^{1}$

\footnotetext{
${ }^{1}$ Department of Internal Medicine III, University Hospital Regensburg, Regensburg, Germany

${ }^{2}$ Chair of Experimental Medicine and Therapy Research, University of Regensburg, Regensburg, Germany

${ }^{3}$ Institute of Radiology, University Hospital Regensburg, Regensburg, Germany

${ }^{4}$ Intana Bioscience GmbH, Martinsried, Germany

${ }^{5}$ Department of Nuclear Medicine, University Hospital Regensburg, Regensburg, Germany

${ }^{6}$ Chair of Pharmaceutical Radiochemistry, Technische Universität München, Munich, Germany

${ }^{7}$ SCINTOMICS GmbH, Fuerstenfeldbruck, Germany

${ }^{8}$ Department of Neurology, University Hospital Regensburg, Regensburg, Germany

${ }^{9}$ Wilhelm Sander-Neurooncology Unit, University Hospital Regensburg, Regensburg, Germany

${ }^{10}$ Department of Neurology 1, NeuroMed Campus, Kepler University Hospital Linz, Linz, Austria

${ }^{11}$ Department of Neuropathology, University Hospital Regensburg, Regensburg, Germany

${ }^{12}$ University Medical Center Göttingen, Department of Medical Statistics, Göttingen, Germany

${ }^{13}$ University Medical Center Göttingen, Department of Hematology and Oncology, Göttingen, Germany

${ }^{14}$ Division Personalized Tumor Therapy, Fraunhofer Institute for Toxicology and Experimental Medicine, Regensburg, Germany

Correspondence to: Tobias Pukrop, email: tobias.pukrop@ukr.de

Keywords: NSCLC; brain metastasis; pentixafor PET/CT; CXCR4; fluorescence cross correlation spectroscopy
}

Received: November 16, $2017 \quad$ Accepted: February 27, $2018 \quad$ Published: April 10, 2018

Copyright: Lüke et al. This is an open-access article distributed under the terms of the Creative Commons Attribution License 3.0 (CC BY 3.0), which permits unrestricted use, distribution, and reproduction in any medium, provided the original author and source are credited.

\section{ABSTRACT}

Brain and leptomeningeal metastasis (LMM) of non-small cell lung cancer is still associated with poor prognosis. Moreover, the current diagnostic standard for LMM often yields false negative results and the scientific progress in this field is still unsatisfying.

We present a case of a 71-year old patient with an isolated LMM. While standard diagnostics could only diagnose a cancer of unknown primary, the use of $\left[{ }^{68} \mathrm{Ga}\right]-$ Pentixafor-PET/CT (CXCR4-PET/CT, a radiotracer targeting CXCR4) and a liquid biopsy of the cerebrospinal fluid revealed the primary NSCLC. The detection of L858R-EGFR, a common driver mutation in NSCLC, enabled us to treat the patient with Afatinib and monitor treatment using $\left[{ }^{68} \mathrm{Ga}\right]-P e n t i x a f o r ~ P E T / C T$. To estimate the impact of CXCR4 signaling and its ligands in NSCLC brain metastasis we looked at their expression and correlation with EGFR mutations in a primary and brain metastasis data set and investigated the previously described binding of extracellular ubiquitin to CXCR4. 
In conclusion, we describe a novel approach to improve diagnostics towards LMM and underline the impact of the CXCL12/CXCR4 axis in brain metastasis in a subset of NSCLC patients. We cannot confirm a correlation of CXCR4 expression with EGFR mutations or the binding of extracellular ubiquitin as previously reported.

\section{INTRODUCTION}

Brain metastasis (BM) and lepto-meningeal metastasis (LMM) of non-small cell lung cancer (NSCLC) is a severe clinical problem with significant impact on quality of life (QoL) and overall survival (OS). With the current local, intrathecal or systemic treatment approaches the 5 -year overall survival is still only $15 \%$ in NSCLC patients with BM and less than $1 \%$ for patients with LMM [1]. At initial diagnosis about $7-10 \%$ of metastasized NSCLC patients already suffer from BM and overall $20-40 \%$ of the patients develop BM during the course of their disease [1]. In contrast to its clinical significance, the scientific efforts were barely noticeable in the past decades. Above all, patients with BM and specifically with LMM were categorically excluded from most clinical trials.

However, especially LMM requires more intensive scientific attention, because even diagnosing LMM is often difficult. This is especially true, when the disease presents in an occult fashion, if tumor material is difficult to reach for the acquisition of histologic material or the patient's condition does not allow invasive procedures. Particularly for these scenarios, innovative, minimallyinvasive diagnostic strategies are needed, especially in the era of "precision medicine" where a molecular diagnosis is obligatory for targeted therapy of NSCLC patients.

The current diagnostic standard of LMM patients are a neurological exam, a MRI of the brain and the neuroaxis and repeated classical cerebrospinal fluid (CSF) analyses, where cell count, glucose and protein levels and sometimes tumor markers are measured and a cytological investigation is performed. However, these classical methods are flawed by a significant diagnostic gap and can yield false negative results in LMM patients. Moreover, in most cases the current techniques are not suitable to detect specific genetic mutations due to the low count of tumor cells in the CSF. In this context, a liquid biopsy of the CSF is a reasonable option to improve diagnostics and eventually outcome of patients with LMM of NSCLC. By definition liquid biopsies, usually performed in, but not limited to blood samples, try to detect tumor specific genetic alterations outside a solid tumor or metastasis [2]. Current investigations demonstrate the diagnostic potential and power of CSF liquid biopsies, employing several different strategies. The CSF sample can be divided into a cellular and a cell free compartment. From both compartments, useful information can be extracted. By removal of the cellular compartment a relative enrichment of circulating tumor DNA (ctDNA) can be achieved in the cell free supernatant. CtDNA is more abundant in CSF than in plasma in patients with primary brain tumors and LMM and metastases that are connected to CSF [3]. This ctDNA can then be used to identify tumor specific mutations [4]. Another approach is to focus on the cellular compartment of CSF. The quality of the DNA is usually higher and less fragmented than in the cell free supernatant. The downside of this approach is the high amount of germline DNA contaminating the samples when total DNA is extracted [4]. A third strategy tries to overcome this limitation by enriching circulating/ disseminated tumor cells, for example by selecting for the epithelial marker EpCAM [5]. With these techniques, an upfront evaluation of tumor biology/origin can be made, pointing clinicians into the right direction to consolidate their diagnosis.

Especially when staging patients with primary NSCLC $\left[{ }^{18} \mathrm{~F}\right]$ FDG-PET/CT is currently the most sensitive tool and several guidelines incorporate $\left[{ }^{18} \mathrm{~F}\right]$ FDG-PET/CT from the very beginning defining of the correct stage of the patients $[6,7]$. $\left[{ }^{18} \mathrm{~F}\right] \mathrm{FDG}-\mathrm{PET} / \mathrm{CT}$ has proven its value, especially when dealing with so-called solitary pulmonary nodules (SPN). The literature reports a sensitivity of about $89 \%$ and a sensitivity of about $75 \%$ for SPNs as small as $8-10 \mathrm{~mm}$ [8]. On the other hand, there are some limitations to this technique. Firstly, it measures the glucose metabolism of the tissue as a surrogate parameter for its proliferative activity. Tumors with a low glucose metabolism might be missed. Secondly, metastases in tissues using glucose very intensively in their physiological state will be missed. This is especially true for BM, as the brain is almost solely dependent on glucose for energy generation [8].

In order to achieve a better diagnostic result, alternative radiotracers are of interest. Besides energy metabolism, there are numerous targets that are upregulated in NSCLC. One is the chemokine receptor 4 (CXCR4) which we previously demonstrated to be upregulated in BM of NSCLC and breast cancer patients [9]. Additionally, there is evidence that CXCR4/ CXCL12 signaling is also a target of EGFR signaling. Tsai et al. showed that expression of L858R-EGFR in lung cancer cell lines, resulted in upregulation of CXCR4. This resulted in increased invasion in a modified Boyden chamber experiment as compared to wild-type expressing EGFR cell lines. They were also able to underline the connection of L858R-EGFR signaling to CXCR4 signaling by using an siRNA directed against CXCR4 and rescuing the invasive effect [10]. CXCR4 is also upregulated in malignant hematological diseases and involved in the regulation of the blood stem cell compartment [11, 12]. In line with these findings recently 
introduced CXCR4-targeted PET/CT imaging by means of the high affinity CXCR4 ligand $\left[{ }^{68} \mathrm{Ga}\right]$-Pentixafor $[13,14]$ has been already proven to be complementary for diagnostic use in myeloma patients [15] compared to standard $\left[{ }^{18} \mathrm{~F}\right] \mathrm{FDG}-\mathrm{PET} / \mathrm{CT}$ [16]. Moreover, CXCR4 is a new immune-oncological target in the treatment of multiple myeloma, myeloid and solid cancers. New antiCXCR4 antibodies or CXCR4 inhibitors are already in early clinical trials (e.g. NCT01359657, NCT01236144, NCT02765165). However, in patients with solid tumors the sensitivity of $\left[{ }^{68} \mathrm{Ga}\right]$ Pentixafor-PET/CT seems inferior to $\left[{ }^{18} \mathrm{~F}\right] \mathrm{FDG}-\mathrm{PET} / \mathrm{CT}$ in a small clinical study [17], although there is evidence, that for some patients there might be a clinical benefit [18].

CXCR4 is a G-protein coupled receptor with two known ligands, namely CXCL12 (SDF-1) and macrophage migration inhibitory factor (MIF) [19, 20]. CXCL12 is regarded the main ligand of CXCR4, while MIF binds to heteromers containing CXCR4, CD74 and CXCR2 [21]. Signaling of CXCR4 influences a variety of cellular pathways, including Gi-mediated inhibition of cAMP production, IP3-stimulated $\mathrm{Ca}^{2+}$ release, JAK/STAT signaling, PI3K/Akt and ERK signaling. Through these pathways CXCR4 signaling is involved in several crucial cell functions, including survival, growth, chemotaxis and also metastasis $[22,23]$. Besides its physiological ligands, there is also evidence, that extracellular ubiquitin is a danger associated molecular pattern (DAMP) signal which might bind to and activate CXCR4 [24]. This finding could have enormous impact in particular in the tumor context, because of the high rate of cell damage and subsequent non-physiological amount of extracellular ubiquitin. Extracellular ubiquitin has further been shown to induce chemotaxis of monocytes and macrophages to a similar extent as CXCL12 [25]. Therefore, released ubiquitin from the necrotic center/cells of a tumor might be the most important source for CXCR4 activation and might additionally influence the composition of the tumor microenvironment. Since CXCR4 activation appears not to be limited to its physiological ligands [21], it is of great interest to identify the CXCR4 activators in the tumor to better stratify the use of "under investigation" CXCR4 inhibitors.

Here, we report a very uncommon case of LMM of a NSCLC patient which has led us to use liquid biopsy of CSF to identify an EGFR mutation and to explore the

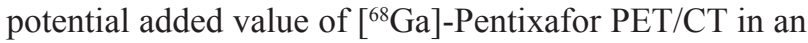
$\left[{ }^{18} \mathrm{~F}\right]$ FDG-PET/CT negative NSCLC.

\section{RESULTS}

\section{Clinical report}

In July of 2015 a 71-year old woman was admitted to hospital with nausea, vomiting, tendency to fall, holocephalgia, partial memory loss and diplopic images.
This set of symptoms had developed within 8 weeks. Additionally, she had been suffering from night sweats for the last 6 months and had experienced a moderate loss of weight of about $2 \mathrm{~kg}$. Cranial MRI showed signs of a CSF circulation disorder (Figure 1A-1C, Supplementary Figure 1).

The analysis of CSF showed normal levels for cell count, protein and glucose. Intrathecal lactate was slightly elevated, hinting a non-specific intrathecal pathology. On neuropathological work-up, the conventional cytomorphological analysis revealed single atypical cells that proved to be cytokeratin 18 and TTF-1 positive on immunocytochemical stains (Figure 1D, 1E). With this staining result at hand, the primary lesion is most probably derived from an adenocarcinoma of the lung.

In a $\mathrm{CT}$ scan of the thorax an intrathoracic mass in the left upper lobe of the lung was detected (Figure $1 \mathrm{G})$. An $\left[{ }^{18} \mathrm{~F}\right]$ FDG-PET/CT however showed no tracer enhancement in this lesion (Figure $1 \mathrm{~F}, 1 \mathrm{H}$ ) and a transbronchial biopsy of the lesion did not reveal any sign of malignancy (data not shown).

\section{Single tumor cell mutational analysis in a CSF liquid biopsy reveals an EGFR-L858R missense mutation}

Next, we chose to analyze the peripheral blood and CSF by a liquid biopsy for the presence of circulating tumor cells (CTCs) from blood and disseminated cancer cells (DCCs) from CSF and to genetically characterize them by targeted sequencing. For this, cancer cells were enriched and detected using the CellSearch system that first enriches them by magnetic capture after anti-EpCAM ferrofluid labeling and visualizes cytokeratin-positive, CD45-negative tumor cells. Interestingly, tumor cells were only detected in CSF but not in peripheral blood (Figure 2A). In total, 14 DCCs were found in CSF, of which 10 were successfully isolated and individually subjected to whole genome amplification. Nine of these ten cells displayed high genome quality, as measured by the genomic integrity index GII [26], indicating that DCCs in CSF are more viable than CTCs in blood. Three cells with highest DNA quality (GII4) were selected for targeted sequencing of EGFR Exon 21 and we identified an EGFR-L858R missense mutation that is common in adenocarcinoma of NSCLC in two out of three DCCs (Figure 2B, Supplementary Figure 2).

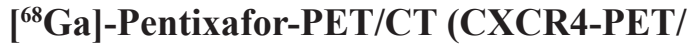 CT) imaging identifies an $\left[{ }^{18} \mathrm{~F}\right]$ FDG-PET/CT negative pulmonary lesion as primary tumor}

Knowing that EGFR-L858R mutations have been shown to enhance the expression of CXCR4 [10], we

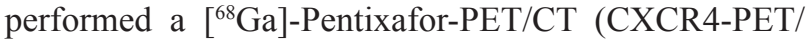
CT) scan. Using this method, we identified the pulmonary 
lesion seen on the CT scans (Figure 1G) as the probable primary tumor. The meningeal affection that initially led to hospitalization of the patient showed no increased $\left[{ }^{68} \mathrm{Ga}\right]$-Pentixafor-PET/CT uptake, probably because the patient had already received 2 courses of intrathecal chemotherapy up to this point (Figure 1I, 1J). After having established a precise diagnosis the patient was treated with Afatinib $40 \mathrm{mg}$ for 8 weeks. Afatinib is a second
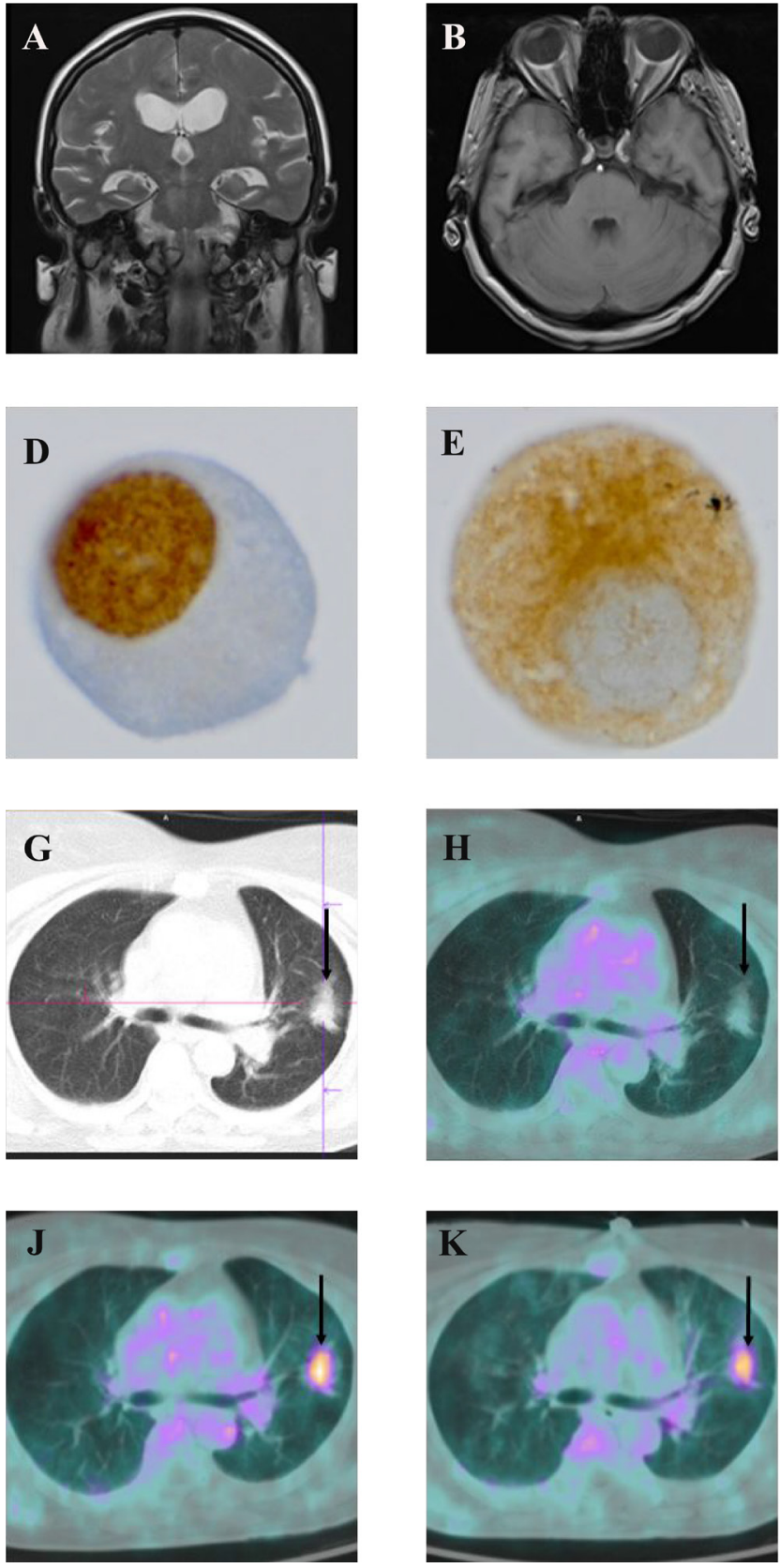
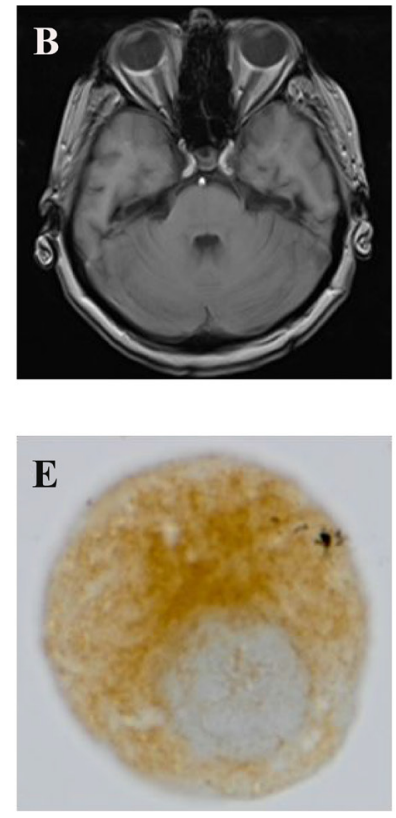

$\mathbf{F}$
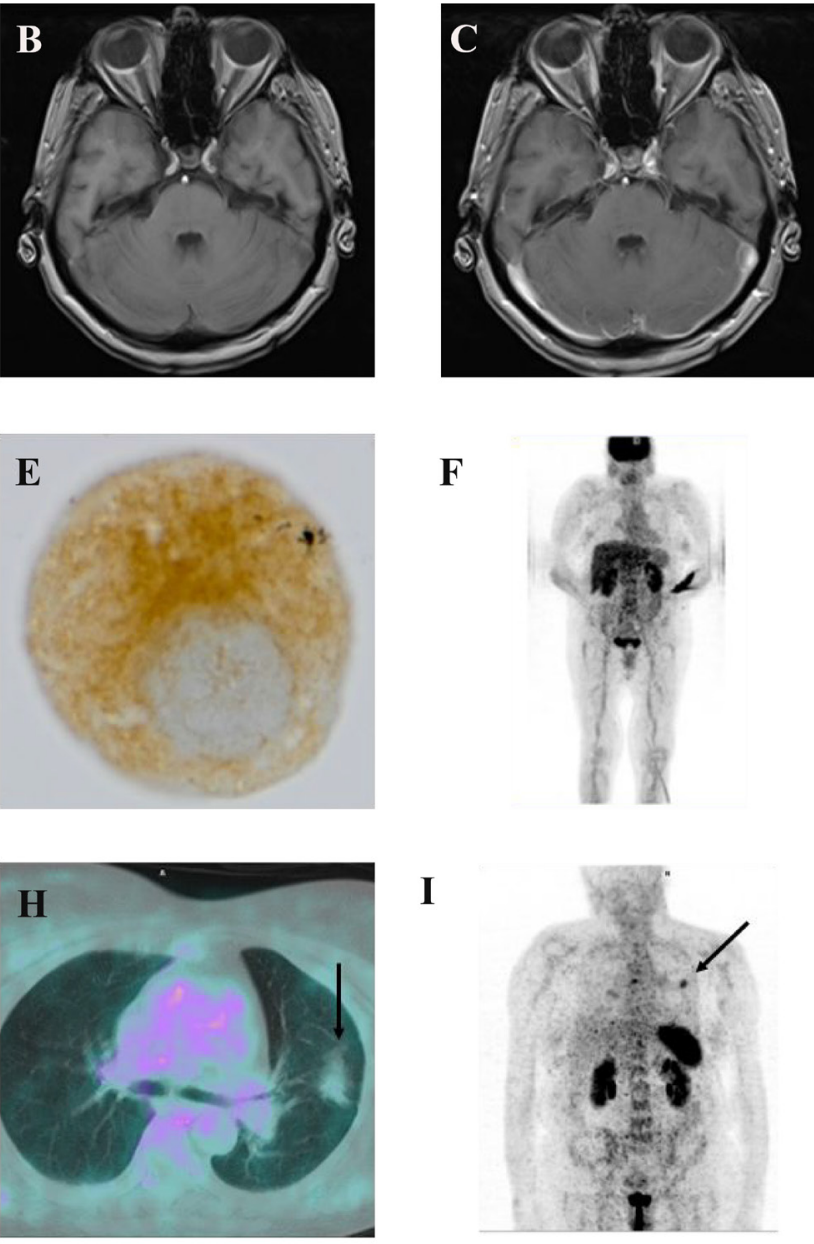

Figure 1: Clinical panel. Coronal T2 MRI image showing signs of a CSF circulation disorder with ventriculomegaly and crowding of the gyri at the vertex with small sulci (A-C) axial T1 MRI images non contrast enhanced (B) and Gadobutrol enhanced (C) showing a representative section of the brain demonstrating no mengingeal enhancement and thus no MR-tomographic sign of meningeal carcinomatosis; (D-E) 1000x magnification of a single tumor cell in the cerebrospinal fluid, immunohistochemistry for TTF1 (D), immunohistochemistry for cytokeratin 18 (E) $\left[{ }^{18} \mathrm{~F}\right] \mathrm{FDG}-\mathrm{PET} / \mathrm{CT}$ scan showing no pathological pulmonal enhancement; (F): representative axial CT-image of the thorax showing an intrathoracal mass (arrow) (G) merged axial [ $\left.{ }^{18} \mathrm{~F}\right] \mathrm{FDG}$-PET, CT image showing no tracer uptake in the intrathoracal mass (arrows); (H) $\left[{ }^{68} \mathrm{Ga}\right]$-Pentixafor (CXCR4) PET scan showing a thoracal tracer enhancement in the left upper thorax (arrow), (J) representative axial merged $\left[{ }^{68} \mathrm{Ga}\right]$-Pentixafor-PET, CT image showing tracer enhancement of the thoracal mass (arrow); $(\mathbf{K})$ representative axial merged $\left[{ }^{68} \mathrm{Ga}\right]$ Pentixafor-PET, CT image 8 weeks after TKI treatment initiation, showing no significant reduction of tracer enhancement. 
generation tyrosine kinase inhibitor used for treatment of EGFR mutated NSCLC. Its ability to cross the blood brain barrier made it the drug of choice for our patient. The following $\left[{ }^{68} \mathrm{Ga}\right]$-Pentixafor-PET/CT was used for therapy monitoring and demonstrated a persistent tumoral uptake of ${ }^{68} \mathrm{Ga}$-Pentixafor and no change in the size of the pulmonary target lesion according to RECIST criteria, suggesting no metabolic sign of treatment response and radiologically stable disease (Figure 1K). Because of treatment related side effects, a Karnofsky Performance Status (KPS) of 50\%, lack of clinical improvement and no changes in ${ }^{68} \mathrm{Ga}$-Pentixafor uptake, we discontinued Afatinib.

\section{EGFR mutation does not necessarily lead to enhanced CXCR4 expression in lung cancer primaries}

Because of this experience and the potential dependency of CXCR4 expression on EGFR-stimulation [10], we asked if activating EGFR mutations in NSCLC primaries generally correlate with elevated CXCR4 expression. Using publicly available data from previously published Microarray analyses we tested our hypothesis in silico. Firstly, we correlated the expression of CXCR4 in a Microarray data set of NSCLC primaries with the EGFR wildtype $(n=192)$ and EGFR mutated $(n=30)$ cohort, which resulted in no significant difference $(q=0.8)$ (Table 1). Secondly, using data from the same gene set, we performed a bioinformatics analysis to assess a correlation between CXCR4 and EGFR gene expression levels. We could not show any significant correlation between these two parameters (Figure 3, Table 3).

On the other hand, the analysis of the physiological ligands, namely CXCL12 and MIF, showed a significant correlation between CXCR4 and CXCL12 expression (Figure 3, Table 3). There was also a significant correlation between CD68 and CXCR4 expression in these samples (Figure 3, Table 3). With the central nervous system (CNS) being a compartment with considerably reduced immune reaction, we hypothesized that there might be a different expression pattern in BM and repeated our in silico testing with samples from brain metastases. Using Affymetrix expression data from 29 lung and 22 breast carcinoma brain metastases [9], we again were unable to find a correlation between CXCR4 and EGFR expression (Figure 4, Table 2). Interestingly, again CXCR4 expression correlated with the expression of CXCL12 (Figure 4, Table 2).

\section{Extracellular ubiquitin does not co-localize with CXCR4 and does not compete with CXCL12 for CXCR4 binding in a FCCS approach}

Finally, we were interested in possible alternative ligands of CXCR4. We looked at extracellular ubiquitin in closer detail because it has been shown to be a DAMP signal for tissue damage and hypoxia and it plays a role in B-cell and monocyte function $[27,28]$. This might be
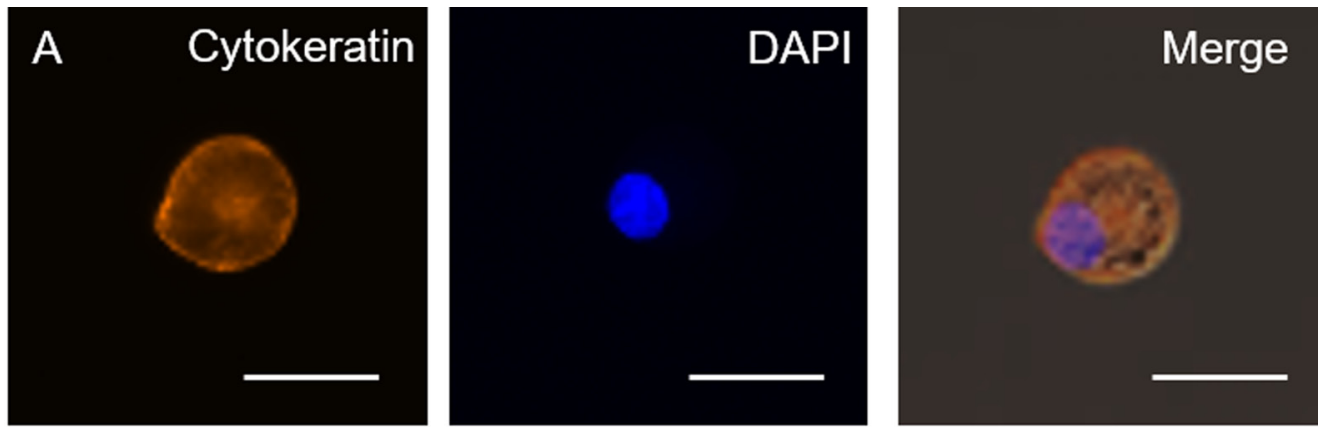

B

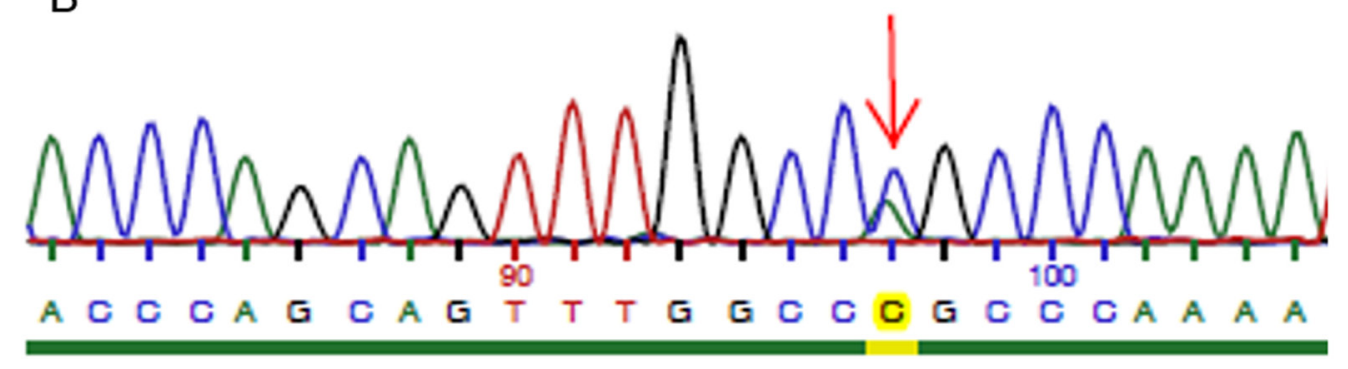

Figure 2: CSF liquid biopsy results. (A) Disseminated tumor cell (DTC) isolated from cerebrospinal fluid of the patient. Staining against EpCAM and DAPI respectively; merged image of EGFR Exon 21 sequencing of an isolated DTC. Arrow indicates the position of the mutation using (L858R missense mutation) antisense sequencing primers (B). Scale bars represent $25 \mu \mathrm{m}$. 
Table 1: Tabular results of a correlation analysis between EGFR wt and EGFR mut lung adeno and squamous cell carcinoma primary samples

\begin{tabular}{lcccccc}
\hline Gene & $\operatorname{logFC}$ & Average Expression & $\begin{array}{c}\text { mean. } \\
\text { EGFRmt }\end{array}$ & mean.EGFRwt & $\boldsymbol{p}$-Value & $\boldsymbol{q}$-Value \\
\hline CXCL12 & -0.06 & 7.33 & 7.28 & 7.34 & 0.67 & 0.93 \\
GFAP & 0.01 & 5.74 & 5.75 & 5.74 & 0.74 & 0.95 \\
MIF & -0.27 & 12.14 & 11.91 & 12.18 & 0.08 & 0.59 \\
EGFR & -0.19 & 7.45 & 7.29 & 7.48 & 0.32 & 0.80 \\
CD68 & -0.10 & 10.75 & 10.66 & 10.76 & 0.48 & 0.87 \\
CXCR4 & -0.14 & 7.40 & 7.28 & 7.42 & 0.32 & 0.80 \\
\hline
\end{tabular}

LogFC representing the $\log _{2}$ fold change in expression.

especially interesting in tumors, as they often contain a hypoxic, necrotic center region where one would suspect big amounts of extracellular ubiquitin. Ubiquitin is a highly conserved and ubiquitous intracellular protein that is released into the extracellular space in cases of tissue damage [24]. Recently extracellular ubiquitin was described as alternative ligand for CXCR4 and therefore as an endogenous DAMP signal with CXCR4 being an allosterically modulated DAMP receptor [29-32]. To test binding of ubiquitin to CXCR4 we used fluorescencelabeled CXCL12, fluorescence-labeled ubiquitin and GFP-tagged CXCR4 in HEK293 cells. While CXCL12 co-localized with CXCR4 (Figure 5A, 5B), the labeled ubiquitin did not (Figure 5C). It rather showed a diffuse intracellular localization after 20 minutes of incubation (Figure 5D). Next, we tested if ubiquitin is a competitive

\section{Lung Cancer Primaries \\ (Adenocarcinoma $\mathrm{n}=96$ )}
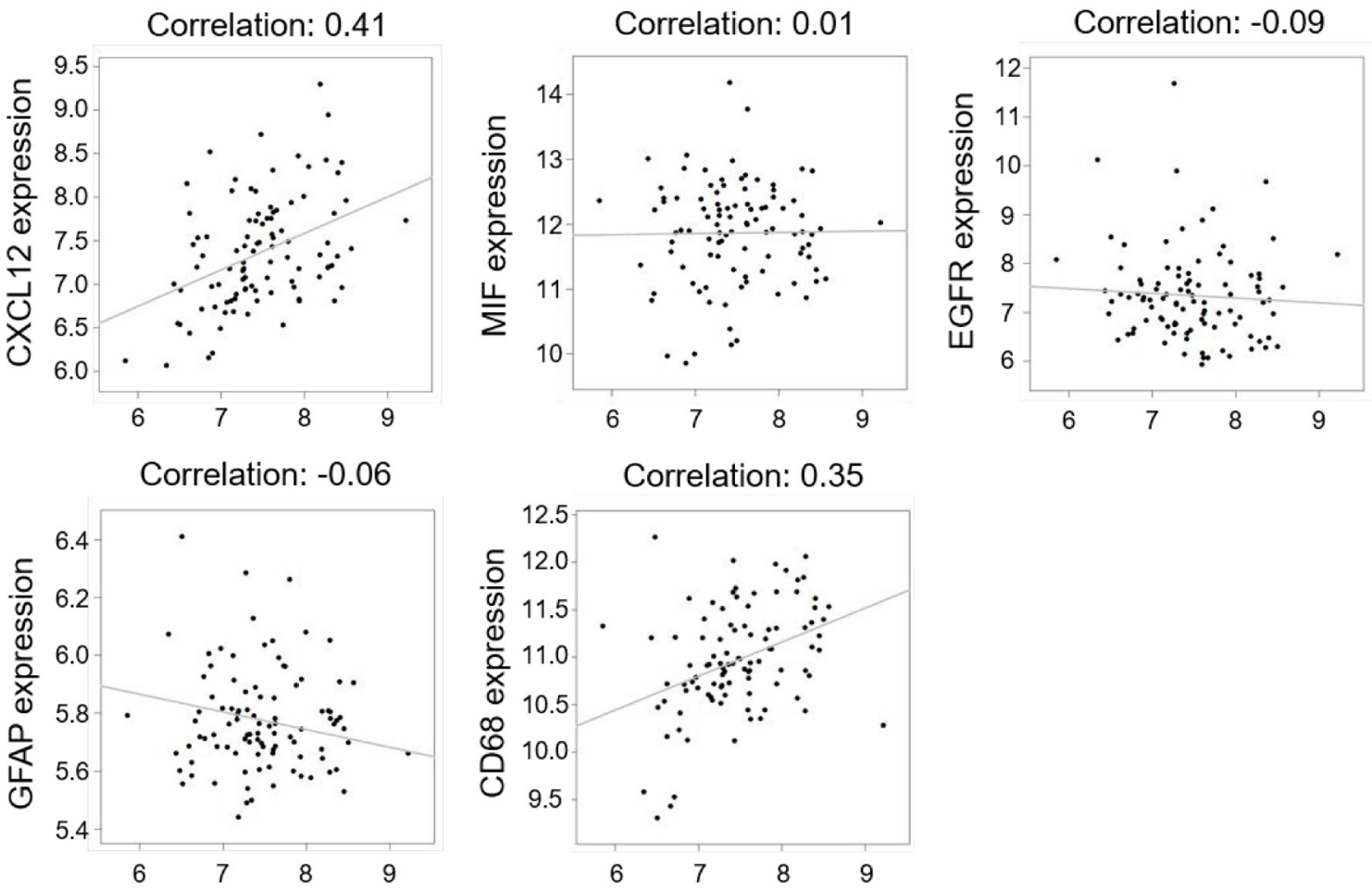

CXCR4 expression

Figure 3: Correlation studies on lung cancer primaries. Analysis of microarray data from lung adenocarcinoma primaries. Scatterplots represent expression of 96 samples on the comparison between CXCR4 and 5 genes (CXCL12, MIF, EGFR, GFAP, CD68), the Pearson correlation coefficients between them are shown as fitting slop lines on each panel. $Q$-values represent the adjusted $p$-value modified for multiple testing using the Bonferroni-approximation. 
Table 2: Tabular results of a correlation analysis between CXCR4 expression and CXCL12, MIF, EGFR, GFAP, CD86 in brain metastastatic samples

\begin{tabular}{lcccc}
\hline Metastatic sample & $\begin{array}{c}\text { Gene expression compared } \\
\text { to CXCR4 }\end{array}$ & $\begin{array}{c}\text { Correlation } \\
\text { coefficient }\end{array}$ & $\boldsymbol{p}$-Value & $\boldsymbol{q}$-Value \\
\hline \multirow{3}{*}{ Lung } & CXCL12 & 0.405 & 0.033 & 0.491 \\
cancer & MIF & -0.387 & 0.042 & 0.627 \\
$(n=28)$ & EGFR & -0.418 & 0.027 & 0.404 \\
& GFAP & -0.195 & 0.319 & 1 \\
& CD68 & -0.327 & 0.089 & 1 \\
& CXCL12 & 0.577 & 0.005 & 0.074 \\
Breast cancer $(n=22)$ & MIF & 0.097 & 0.667 & 1 \\
& EGFR & 0.288 & 0.193 & 1 \\
& GFAP & 0.087 & 0.700 & 1 \\
& CD68 & 0.181 & 0.420 & 1 \\
Lung cancer and & CXCL12 & 0.449 & 0.001 & 0.016 \\
breast cancer combined & MIF & -0.270 & 0.058 & 0.869 \\
& EGFR & -0.110 & 0.447 & 1 \\
& GFAP & -0.130 & 0.368 & 1 \\
\hline
\end{tabular}

Table 3: Tabular results of a correlation analysis between CXCR4 expression and CXCL12, MIF, EGFR, GFAP, CD68 in lung adenocarcinoma primary samples

\begin{tabular}{lcccc}
\hline Primary lung cancer sample & $\begin{array}{c}\text { Gene expression } \\
\text { compared to CXCR4 }\end{array}$ & $\begin{array}{c}\text { Correlation } \\
\text { coefficient }\end{array}$ & $\boldsymbol{p}$-Value & $\boldsymbol{q}$-Value \\
\hline \multirow{2}{*}{ Adeno-carcinoma } & CXCL12 & 0.41 & $1.79 \times 10^{-5}$ & $5.3 \times 10^{-4}$ \\
$(n=96)$ & MIF & 0.01 & 0.86 & 1 \\
& EGFR & -0.09 & 0.34 & 1 \\
& GFAP & -0.06 & 0.55 & 1 \\
& CD68 & 0.36 & 0.00029 & $8.9 \times 10^{-3}$ \\
NSCLC & CXCL12 & 0.49 & $1.05 \times 10^{-14}$ & $3,14 \times 10^{-13}$ \\
$(n=220)$ & MIF & 0.01 & 0.84 & 1 \\
& EGFR & -0.055 & 0.41 & 1 \\
& GFAP & -0.01 & 0.83 & 1 \\
\hline
\end{tabular}

ligand to CXCR4 by a FCCS approach. Our results show that ubiquitin can neither displace CXCR4's innate ligand CXCL12 nor a CXCR4 monoclonal antibody from the chemokine receptor (Figure 5E, 5F). This suggests no direct competition for the CXCL12 binding site. Since this does not rule out an allosteric mechanism of ubiquitin action on CXCR4 we proceeded to test the binding affinity of CXCL12 in the presence and absence of ubiquitin. Yet again we could not find a change in receptor binding kinetics (Figure 5G, 5H).

\section{DISCUSSION}

This uncommon case report of a $\left[{ }^{18} \mathrm{~F}\right]$ FDG-PET/ CT negative NSCLC patient, who presented with isolated
LMM illustrates the current limitations of the standard of diagnostics for LMM patients. Moreover, it also emphasizes that particularly patients with an unusual course of NSCLC do profit more from innovative diagnostic techniques, like liquid biopsy of CSF and innovative imaging methods. However, these rare courses of NSCLC are usually not considered for clinical trials. Thus, the current study designs with very strict inclusion criteria harbor a risk that a potential added value for these patients with innovate techniques will be completely overlooked. In contrast, our further bioinformatics analyses also taught us that general conclusions from case reports should be handled carefully [10]. We assumed, that there was a link of CXCR4 expression and the mutation status of EGFR, and had therefore implemented 


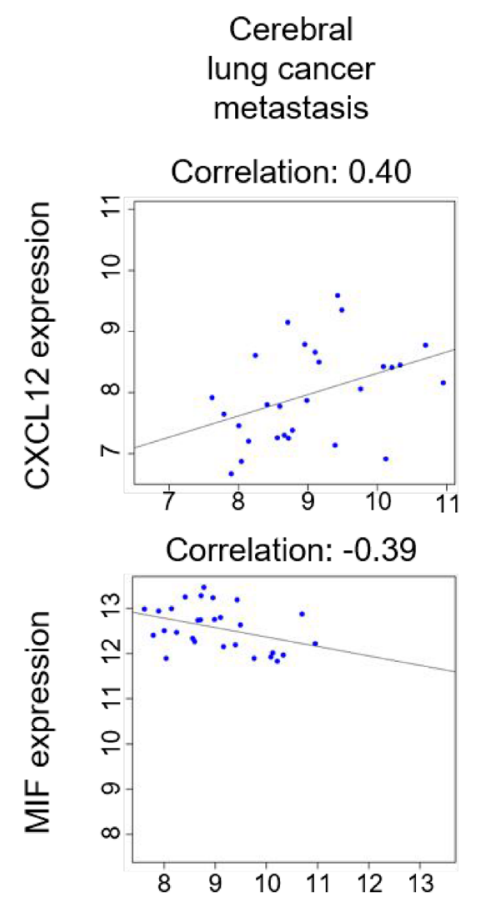

\section{Cerebral \\ breast cancer \\ metastasis}

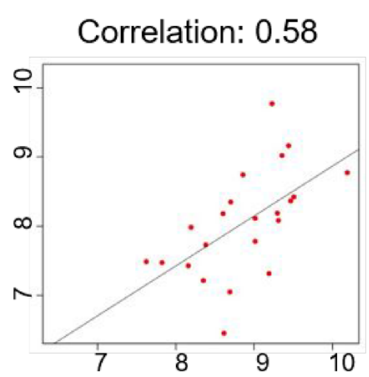

Correlation: 0.10

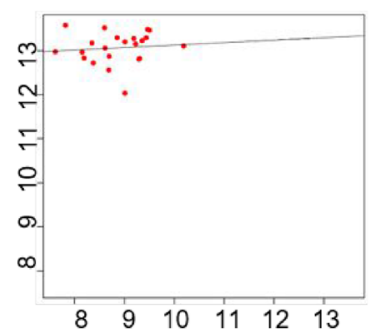

Correlation: 0.29

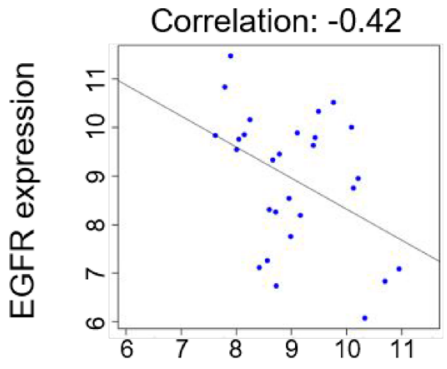

Correlation: -0.20
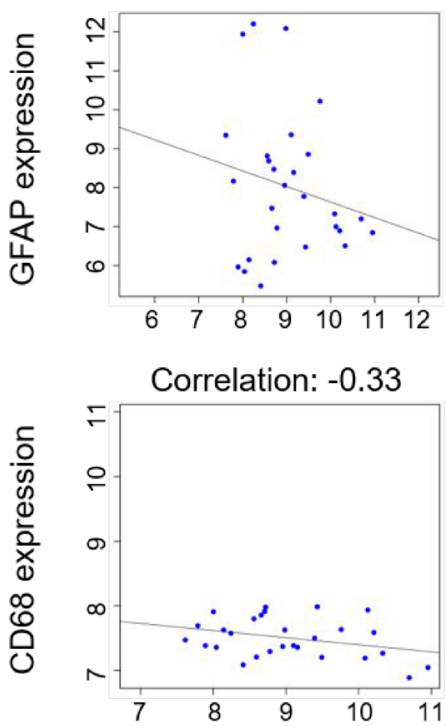

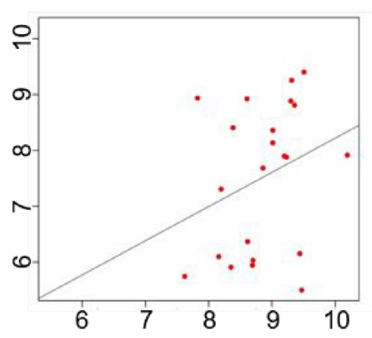

Correlation: 0.09

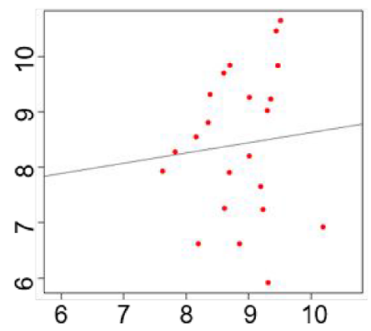

Correlation: 0.18

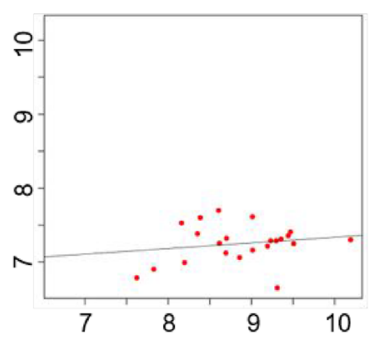

CXCR4 expression
Cerebral lung and breast cancer metastasis

Correlation: 0.45

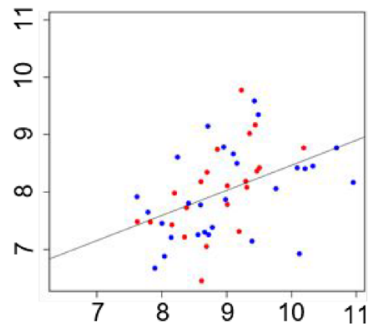

Correlation: -0.27

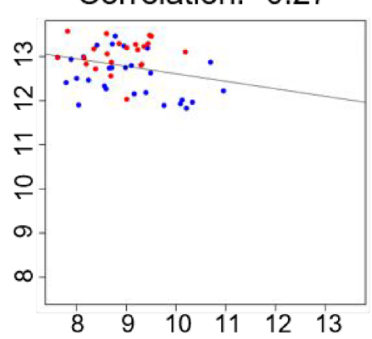

Correlation: -0.11

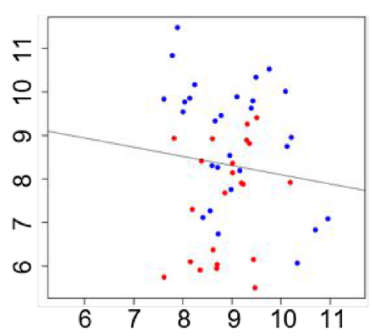

Correlation: -0.13

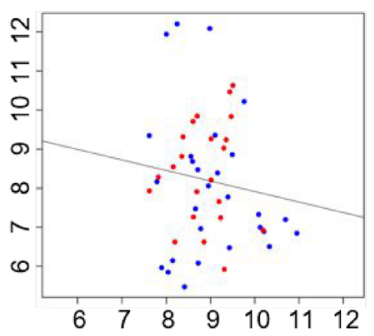

Correlation: -0.11

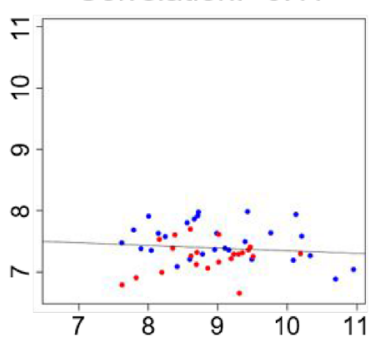

Figure 4: Correlation studies on breast and lung cancer brain metastases. Analysis of Affiymetrix Microarray data from 28 lung cancer metastatic samples and 22 breast cancer metastatic samples. Scatterplots represent expression of the samples on the comparison between CXCR4 and 5 genes (CXCL12, MIF, EGFR, GFAP, CD68), the Pearson correlation coefficients between them are shown as fitting slop lines on each panel. $Q$-values represent the adjusted p-value modified for multiple testing using the Bonferroni-approximation. 
Pentixafor-PET/CT from the beginning. Although the $\left[{ }^{68} \mathrm{Ga}\right]$-Pentixafor-PET/CT revealed the probable primary tumor, the bioinformatics analyses of gene expression data could not support our assumption that CXCR4 expression and the mutation status of EGFR are linked. However, our data do not completely rule out a more complex interaction of CXCR4 and EGFR signaling. Nevertheless, the $\left[{ }^{68} \mathrm{Ga}\right]$-Pentixafor-PET/CT identified the primary tumor in our case and was very useful in treatment follow-up and clinical decisions made. Yet, we aimed to gain a better idea about the clinical circumstances in

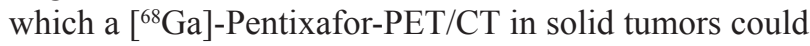
help to diagnose $\left[{ }^{18} \mathrm{~F}\right] \mathrm{FDG}-\mathrm{PET} / \mathrm{CT}$ negative tumors. Therefore, we analyzed selected genes which could be at least theoretically linked to the expression of CXCR4. This analysis revealed that only the physiological ligand CXCL12 correlated with the CXCR4 expression in all tested data sets of the tested genes.

To estimate the potential impact of deregulated CXCR4 activity in tumor tissue, we investigated the
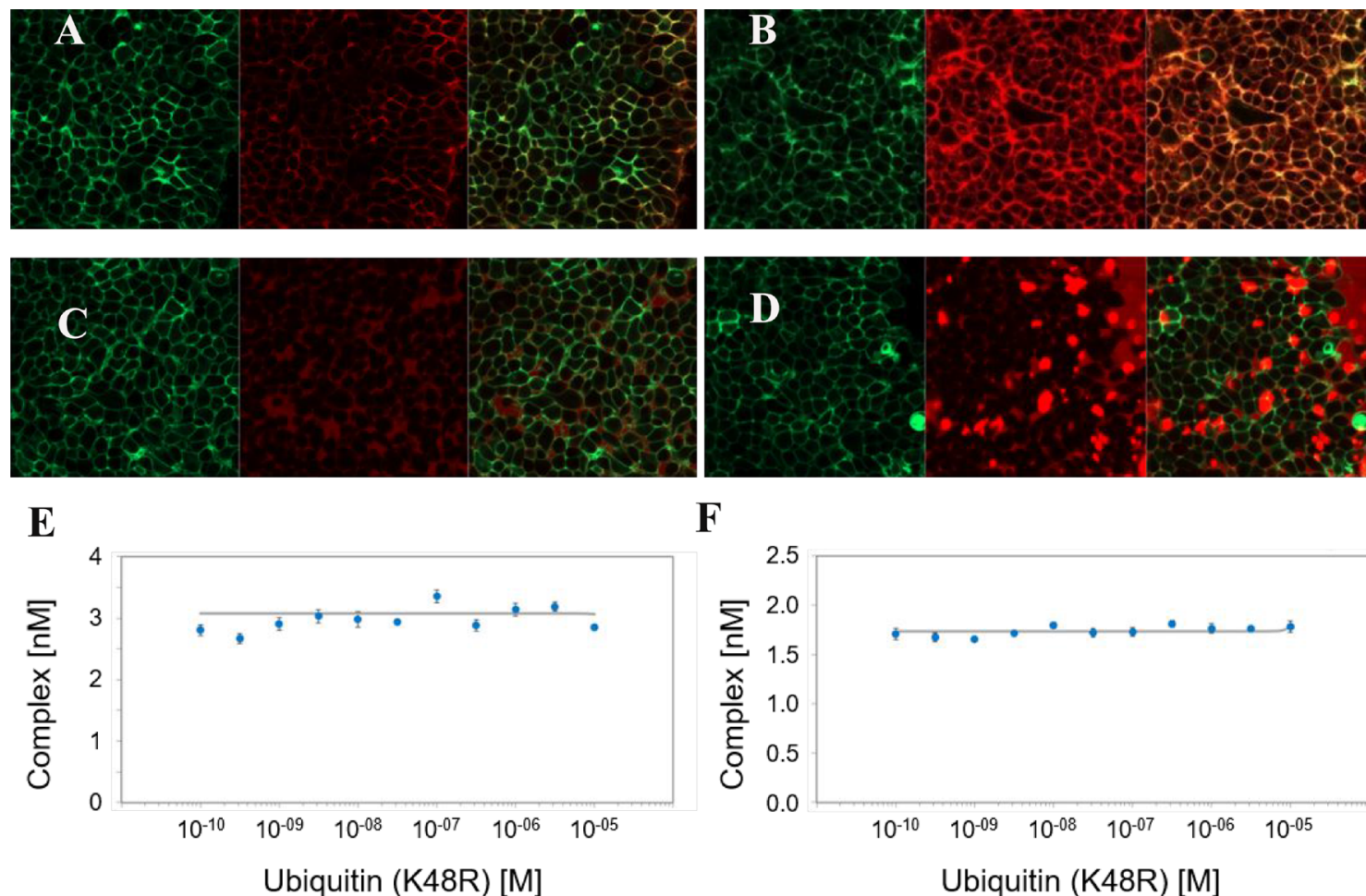

$\mathbf{F}$
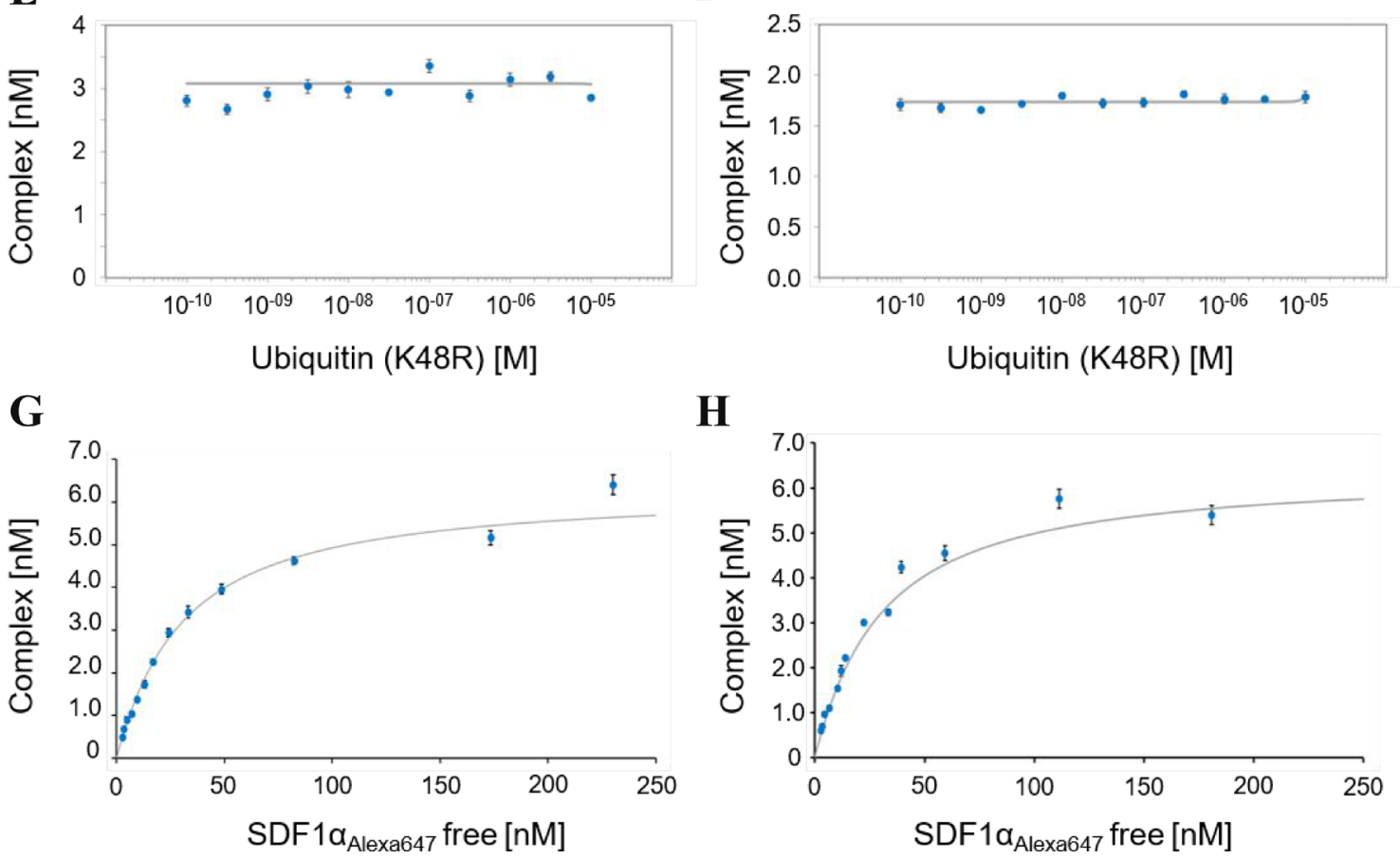

Figure 5: FCCS studies. (A, B) Binding of $50 \mathrm{nM}$ Alexa647 (red color) labeled CXCL12 to CXCR4-GFP (green color) expressing HEK293-cells 2 minutes (A) and 20 minutes (B) after additon of CXCL12 (left panel showing GFP labeled CXCR4, middle panel showing Alexa647 labeled CXCL12, right panel showing the merged image); (C, D) binding of $200 \mathrm{nM}$ Alexa 647 labeled ubiquitin (red color) to CXCR4-GFP expressing HEK293-cells (green color) 2 minutes (C) and 20 minutes (D) after addition of ubiquitin; (left panel showing GFP labeled CXCR4, middle panel showing Alexa647 labeled Ubiquitin, right panel showing the merged image) (E) competition binding assay

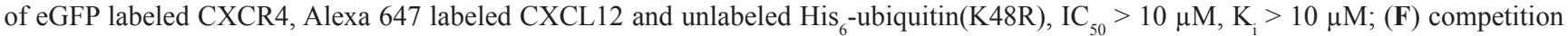
binding assay of eGFP labeled CXCR4, PEG4-DY647 labeled anti-CXCR4mAb and unlabeled His -ubiquitin(K48R), IC $_{50}>10 \mu \mathrm{M}, \mathrm{K}_{\mathrm{i}}$ $>10 \mu \mathrm{M} ;(\mathbf{G}, \mathbf{H})$ saturation binding assay of eGFP labeled CXCR4 and Alexa 647 labeled CXCL12 without ubiquitin $(\mathrm{G})$ and $80 \mu \mathrm{M}$ unlabeld ubiquitin $(\mathrm{H})$. 
recently described alternative DAMP ligand, ubiquitin [30]. Ubiquitin is, due to cell death and necrosis, present in non-physiologically high, extracellular concentrations in tumor tissue and could therefore be the relevant ligand for CXCR4 in a tumor. However, our binding studies of extracellular ubiquitin to CXCR4 showed no direct interaction of CXCR4 with this molecule. We also could not show an allosteric modulation of CXCL12 binding affinity to CXCR4 by our FCCS studies. This is in contradiction with results of Saini et al., who showed that CXCL12 could replace fluorescently labeled ubiquitin from cells in a CXCR4 dependent fashion [30]. We hypothesize that there might be CXCR4 signaling related to extracellular ubiquitin, i.e. by recruiting a second protein to form heterodimers with CXCR4. For example, CXCR4 has been shown to form heterodimers, i.e. with ACKR3 [33]. The analysis of CXCL12 expression could be a very interesting candidate for future stratification not only when using $\left[{ }^{68} \mathrm{Ga}\right]-P e n t i x a f o r-P E T / C T$, but also when considering potential inclusion criteria for CXCR4 inhibitor trials. Recently, beta emitter labeled analogs of CXCR4-ligands ( $\left[{ }^{177} \mathrm{Lu}\right] /\left[{ }^{90} \mathrm{Y}\right]$ Pentixather $)$ have been tested as a novel therapeutic approach in patients with hematological neoplasm (i.e. multiple myeloma). The [68Ga]-Pentixafor-PET/CT in our patient showed a high tracer uptake, so Pentixather could have had a therapeutic benefit, in principle. However due to its strong myeloablative effect CXCR4-directed radionuclide therapy seems not to be of clinical value in this tumor entity [34].

Moreover, our patient's case also demonstrates the potential power of tumor cell enriching liquid biopsies of CSF in LMM patients. When looking at patients with isolated LMM, even if disseminated tumor cells are found in a lumbar puncture, the underlying tumor entity can be precisely identified in a standard cytology assessment, as we demonstrated above. Liquid biopsies using ctDNA and DNA extracted from the cellular compartment do bear limitations: they work best in CSF-cytology positive patients [4]. This still adds significant diagnostic value, but the sensitivity to detect LMM in the first place remains at the level of a single lumbar puncture $(\sim 50 \%)$. By using tumor cell enriching techniques, as in our case, the sensitivity can be significantly enhanced. This is also underlined by a small study in NSCLC patients, which directly compared the sensitivity of MRI (47.6\%), classical CSF-cytology $(57.1 \%)$ and CellSearch enriched DTC analysis (95.2\%) of CSF for diagnosing LMM. Thus, liquid biopsies can help to identify primary tumor origin in patients, that otherwise would have been classified as cancer unknown primary (CUP).

Taken together, since LMM is in most cases a prognosis limiting condition [35] more scientific efforts should be undertaken to implement and validate innovative techniques. In the future, we need such highly precise tools in diagnosing and treating these patients, in particular if they present with an uncommon clinical course. In this context, the liquid biopsy of the CSF and the $\left[{ }^{68} \mathrm{Ga}\right]$-Pentixafor-PET appear to be very promising.

\section{MATERIALS AND METHODS}

\section{Patients and CTC enrichment and detection using the CellSearch ${ }^{\circledR}$ assay}

A blood sample and cerebrospinal fluid were obtained from the patient based on principles set out in the WMA Declaration of Helsinki and approved by the Ethics Committee of University of Regensburg. Enrichment and detection of CTCs was performed using the CellSearch system (Riethdorf et al., 2007). Briefly, $6 \mathrm{ml}$ of CSF and $10 \mathrm{ml}$ of blood were obtained and transferred into a CellSave tube (Veridex Inc.). The CellSearch Epithelial Cell Test (Veridex Inc.) was applied for enrichment and enumeration of circulating tumour cells (CTCs) from blood and disseminated cancer cells (DCC) from CSF according to the instruction from the manufacturer. CTCs are captured from 7.5 $\mathrm{ml}$ of blood by anti-epithelial cell adhesion molecule (EpCAM)-antibody-bearing ferrofluid and subsequently checked for positivity or negativity for cytokeratin, the leukocyte common antigen CD45 and 4',6-diamidino2-2phenylindole (DAPI) staining to ensure the integrity of the nucleus. For enrichment of DCC from CSF we modified the protocol. After puncture, the sample was transferred to a CellSave tube. After a short incubation the sample was transferred to a CellSearch Conical Centrifuge tube and sample preparation using the CellTrack Autoprep - system was started and run similar to a control sample and analysed by CellTracks AnalyzerII.

\section{Isolation of CTCs and WBCs by micromanipulator and microscope}

After epithelial cell enrichment cells from blood or CSF were extracted from CellSearch cartridge using a 200 $\mu l$ gel-tip pre-rinsed in PBS-BSA $2 \%$ and transferred to a new protein LoBind 1.5-ml tube (Eppendorf, Germany). The cartridge was subsequently washed two times using $325 \mu \mathrm{l}$ of PBS (PAN Biotech) and repeatedly pipetting against the inner surface. The complete fluid was transferred to the $1.5-\mathrm{ml}$ sample tube and centrifuged at $1,000 \mathrm{~g}$ for $5 \mathrm{~min}$ in a swinging-bucket rotor centrifuge. After discarding the supernatant by pipetting, $1 \mathrm{ml}$ of PBS was added and the tube again centrifuged at 1,000 $\mathrm{g}$ for 5 min in a swinging-bucket centrifuge. Again the supernatant was removed, and the pellet was finally resuspended in $200 \mu \mathrm{l} \mathrm{PBS}$. The sample was then loaded one field of a BSA (20 mg/ml in $\mathrm{H}_{2} \mathrm{O}$, Sigma-Aldrich) covered glass slide (Nunc ${ }^{\circledR}$ Lab-Tek $^{\circledR}$ Chamber Slide $^{\mathrm{TM}}$ system 8 wells, 
Thermo Fischer) and screened by fluorescence microscopy (IX81, Olympus, Germany). Using the Cy3- and DAPI fluorescence filter the CTCs/DCCs were identified, using the APC and DAPI fluorescence filters the WBCs were identified and both by micromanipulation using a glass capillary of $\approx 30-\mu \mathrm{m}$ diameter pre-rinsed with FCS, transferred to a new BSA covered field with $200 \mu \mathrm{l}$ PBS. Here, by pipetting of $1 \mu \mathrm{l}$, the cells were singly picked into individual $200 \mu \mathrm{l}$ tubes (Nerbe plus, Germany) including $2 \mu \mathrm{l}$ of Proteinase $\mathrm{K}$ digest mix (first step of Whole genome amplification).

\section{Whole genome amplification}

The method is based on a published adaptor-ligationmediated whole genome amplification protocol (Klein et al., 1999, 2002) and has become commercially available as Ampli1-kit (Silicon Biosystems). In brief, after the Proteinase $\mathrm{K}$ digest $\left(10 \mathrm{~h} 42^{\circ} \mathrm{C}\right.$, inactivation for $10 \mathrm{~min}$ at $80^{\circ} \mathrm{C}$ ), single cell DNA was digested by MseI restriction endonuclease $\left(3 \mathrm{~h} 37^{\circ} \mathrm{C}, 65^{\circ} \mathrm{C}\right.$ for $5 \mathrm{~min}$ of inactivation). Adaptor formation by pre-annealing of ddMSE primer and LibI primer was performed with a starting temperature of $65^{\circ} \mathrm{C}$ and shifted down to $15^{\circ} \mathrm{C}$ with a ramp of $1^{\circ}$ $\mathrm{C} / \mathrm{min}$. At $15^{\circ} \mathrm{C}, 1 \mu \mathrm{l}$ of ATP $(10 \mathrm{nM})$ and $1 \mu \mathrm{l}$ of T4DNA-Ligase (5 units) were added and primers and DNA fragments were ligated overnight. Resulting in $50 \mu \mathrm{l}$ of WGA product the primary amplification was started.

\section{Quality control assay}

For the multiplex PCR, $1 \mu$ l WGA template was used in $10 \mu \mathrm{l}$ of a water-based mastermix containing 1x FastStart PCR Buffer (including $\mathrm{MgCL}_{2}$ ), $200 \mathrm{nM}$ dNPTs, $0.5 \mathrm{U}$ FastStart Polymerase and $4 \mu \mathrm{g}$ BSA (all consumables Roche Diagnostics GmbH, Germany). The eight primers (CK19, TP 53 Exon 2/3, D5S2117, KRAS) were each used in an end concentration of $0.4 \mu \mathrm{M}$. PCR was started with a first step at $95^{\circ} \mathrm{C}$ for $4 \mathrm{~min}$, followed by 32 cycles of $95^{\circ} \mathrm{C}$ for $30 \mathrm{~s}, 58^{\circ} \mathrm{C}$ for $30 \mathrm{~s}$ and $72^{\circ}$ $\mathrm{C}$ for $90 \mathrm{~s}$, and final elongation step of $7 \mathrm{~min}$ at $72^{\circ} \mathrm{C}$. To determine the genome integrity index, $\mathrm{PCR}$ products were visualized on a $1.5 \%$ agarose gel. The protocol of the multiplex PCR assay is based on the commercially available Ampli1 ${ }^{\mathrm{TM}} \mathrm{QC}$ kit (Silicon Biosystems, Italy).

\section{Analysis of microarray datasets}

Data were analyzed analogous to [9]. Briefly Affymetrix data sets of 28 brain metastasis samples from primary adenocarcinomas of the lung (GSE 14108) and 22 brain metastasis samples from primary breast cancers (GSE 14017, GSE 14018) were subjected to correlation analysis using the free statistical software R (http://www.rproject.org). The data sets are publicly available on Gene Expression Omnibus (GEO, https://www.ncbi.nlm.nih. gov/geo/query/acc.cgi). The metastases used to generate this data set were profiled and compared by the expression level of over 400 cytokines. If not otherwise specified correlation coefficients and $p$-values were calculated according to the Pearson correlation method supplied by R. $Q$-values given represent corrected $p$-values according to the Bonferroni approximation, to adjust for errors caused by multiple testing. The Bonferroni method was used, for its conservative calculation profile. It usually yields higher $q$-values than other methods used. While disposing some results as insignificant, the probability of a false positive result is greatly reduced. Significance threshold for $p$ - and $q$-values alike is $<0.05$. Correlation analysis of primary lung cancer samples were performed using data from [36]. The source data are available under http://stm.sciencemag.org/content/5/209/209ra153/tabfigures-data and http://www.uni-koeln.de/med-fak/clcgp/.

\section{Fluorescence cross correlation spectroscopy (FCCS) analysis}

Reagents were obtained from Anatrace (Maumee, OH, USA), AppliChem (Darmstadt, Germany), Carl Roth (Karlsruhe, Germany), or SigmaeAldrich (St. Louis, MO, USA) unless stated otherwise. Unlabeled compounds were purchased from Tocris (Bristol, UK) or Abcam (Cambridge, UK) with the exception of $(\neg)$-norepinephrine and SR48692 (SigmaeAldrich), SR 142948A (Santa Cruz Biotechnology, Santa Cruz, CA, USA), neurotensin (8e13) (NT; AnaSpec/MoBiTec, Göttingen, Germany), and TC 14012 (Cayman Chemical, Ann Arbor, MI, USA). Anti-CXCR4 monoclonal antibody clone 44708 (murine IgG2A; cat. no. MAB171) was acquired from R\&D Systems (Minneapolis, MN, USA). Unlabeled recombinant $\mathrm{CXCL12/SDF-1a}$ was obtained as a gift from Annette Beck-Sickinger (Institut für Biochemie, Universität Leipzig, Germany). Human synthetic stromal cell-derived factor 1 (SDF1a) labeled specifically on residue Lys64 with AlexaFluor 647 (henceforth "SDF1aAF647"; cat. no. CAF-11) was acquired from Almac (Craigavon, UK).

FCCS analysis was carried out as described in [37]. Briefly, CXCR4 was expressed as C-terminal fusion to GFP in HEK293 cells. Membranes were prepared by sonification on ice. Cell debris was removed and membranes harvested from the cleared lysate by subsequent centrifugation at $21.000 \mathrm{~g}$. The receptors were solubilized by incubation in detergent mix of DDM (n-dodecyl $\beta$-D-maltoside)/CHAPS/CHS (cholesteryl hemisuccinate). Insolubilized membrane material was removed by centrifugation at $100.000 \mathrm{~g}$. Solubilized GPCRs were directly used for FCCS binding assays.

FCCS measurements with samples at equilibrium were performed with a ConfoCor2 FCS unit connected to an Axiovert 100M equipped with a C-Apochromat $40 \times$ water immersion lens, NA 1.2 (Carl Zeiss, Jena, Germany) whereas FCCS-data for binding kinetics were acquired on 
an Insight plate reader (Evotec Technologies, Hamburg, Germany) fitted with a U-Apo300 40× water immersion lens, NA 1.15 (Olympus, Germany). The kinetics was monitored by FCCS over the course of 20-60 min. For more detailed information see Supplementary methods.

\section{Preparation of $\left[{ }^{68} \mathrm{Ga}\right]$-pentixafor}

$\left[{ }^{68} \mathrm{Ga}\right]$-Pentixafor was synthesized in a fully automated procedure on a Scintomics GRP module (SCINTOMICS GmbH, Germany) connected to a ${ }^{68} \mathrm{Ge} /{ }^{68} \mathrm{Ga}$ generator (iThemba Labs, South Africa) and equipped with a disposable single-use cassette kit (ABX $\mathrm{GmbH}$, Germany) using a standardized labeling sequence [38]. For more detailed information see Supplementary Methods.

\section{$\left[{ }^{18}\right.$ F]FDG PET/CT, ${ }^{68}$ Ga-Pentixafor-PET/CT}

$\left[{ }^{18} \mathrm{~F}\right] \mathrm{FDG}$-PET/CT imaging was performed using a Biograph 16 PET/CT scanner (CTI-Siemens, Erlangen, Germany). After a fasting period of at least $4 \mathrm{~h}, 3 \mathrm{MBq}\left[{ }^{18} \mathrm{~F}\right]$ FDG per kilogram body weight were injected intravenously. After a waiting period of $60 \mathrm{~min}$ post injection the PET/ $\mathrm{CT}$ acquisition was performed. PET images (slice thickness $5 \mathrm{~mm}$ ) were corrected for random coincidences, decay, scatter and attenuation and reconstructed iteratively using the ordered subsets expectation maximization algorithm (OSEM) with 4 iterations and 8 subsets. $\left[{ }^{68} \mathrm{Ga}\right]$-Pentixafor$\mathrm{PET} / \mathrm{CT}$ was performed the same way with an activity of

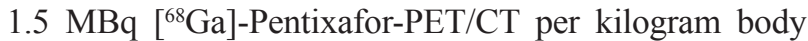
weight without fasting.

\section{Abbreviations}

EGFR: Epithelilal Growth Factor Receptor; NSCLC: Non Small Cell Lung Cancer; LMM: Leptomeningeal metastasis; CUP: Cancer Unknown Primary; PET: Positron Emission Tomography; CT: Computed Tomography; TKI: Tyrosine kinase inhibitor; CSF: Cerebrospinal Fluid; BM: Brain Metastasis; OS: Overall survival; ctDNA: Circulating tumor DNA; DNA: Desoxyribonuclear Acid; EpCAM: Epithelial Cell Adhesion Molecule; SPN: Solitary Pulmonary Nodule; CXCR4: Chemokine Receptor 4; CXCL12:Chemikine Receptor Ligand 12; SDF-1:Stromal Cell Derived Facor 1; MIF: Macrophage Migration Inhibitory Facor; cAMP: Circular Adenosinemonophposphate; CXCR2: Chemokine Receptor 2; IP3: Inositol-1,4,5-trisphpsphat; JAK: Janus Kinase; STAT: Signal Transducer and Activator of Transcription; PI3K: Phosphoinositid-3-Kinase; ERK:Extracellularsignal Regulated Kinase; CTC: Circulating Tumor Cell; DCC: Disseminated Tumor Cell; RECIST: Response Evaluation Criteria In Solid Tumors; KPS: Karnofsky Perfomance Status; CNS: Central Nervous System; FCCS: Fluorescence Cross Correlation Spectroscopy; DAMP: Danger Associated Molecular Pattern; ACKR3: Atypical Chemokine Receptor Kinase 3; MRI: Molecular Resonance
Imaging; GFAP: Glial Fibrillary Acidic Protein; WGA: Whole genome amplification.

\section{Author contributions}

Florian Lüke: Data interpretation, writing and design of the manuscript, data collection, approval of final manuscript version; Raquel Blazquez: Data interpretation, approval of final manuscript version; Rezan Fahrioglu Yamaci: data interpretation of liquid biopsy, approval of final manuscript version; Xin Lu: bioinformatics data interpretation, approval of final manuscript version; Benedikt Pregler: interpretation and aquisition of CT and MRI images, approval of final manuscript version; Stefan Hannus: design and interpretation of FCCS experiments, approval of final manuscript version; Karin Menhart: data interpretation of FDG and CXCR4 PET/CT images, approval of final manuscript version; Dirk Hellwig: data interpretation of FDG and CXCR4 PET/CT images, approval of final manuscript version; Hans-Jürgen Wester: Pentixafor synthesis, approval of final manuscript version; Saskia Kropf: Pentixafor synthesis, approval of final manuscript version; Daniel Heudobler: Data interpretation, approval of final manuscript version; Jirka Grosse: data interpretation of FDG and CXCR4 PET/CT images, approval of final manuscript version; Jutta Moosbauer: synthesis and quality control of Pentixafor, approval of final manuscript version; Markus Hutterer: approval of final manuscript version; Peter Hau: Data interpretation, approval of final manuscript version; Markus J. Riemenschneider: interpretation of CSF cytology, approval of final manuscript version; Michaela Bayerlová: Interpretation of bioinformatics data, approval of final manuscript version; Annalen Bleckmann: Interpretation of bioinformatics data, approval of final manuscript version; Tim Beißbarth: Interpretation of bioinformatics data, approval of final manuscript version; Bernhard Polzer : data interpretation of liquid biopsy, approval of final manuscript version; Christoph A. Klein: design and interpretation of CSF liquid biopsy, approval of final manuscript version; Tobias Pukrop: patient recruitment, informed consent of patient, Data interpretation, writing and design of the manuscript, approval of final manuscript version;

\section{CONFLICTS OF INTEREST}

Authors on position 1-9 and 11-22 declare no conflicts of interest. Authors on position 10 is CEO of Scintomics $\mathrm{GmbH}$, which holds patents for $\left[\mathrm{Ga}^{68}\right]$ Pentixafor.

\section{FUNDING}

German Research Foundation (DFG) research group 942 (BE 2552/8-2) on WNT signaling. German 
Ministry of Education and Research (BMBF) e:Bio project MetastaSys (0316173A).

\section{REFERENCES}

1. Lemjabbar-Alaoui H, Hassan O, Yang YW, Buchanan P. Lung cancer: biology and treatment options. Biochimica et biophysica acta. 2015; 1856:189-210. https://doi. org/10.1016/j.bbcan.2015.08.002.

2. Siravegna G, Marsoni S, Siena S, Bardelli A. Integrating liquid biopsies into the management of cancer. Nat Rev Clin Oncol. 2017; 14:531-548. https://doi.org/10.1038/ nrclinonc.2017.14.

3. Murtaza M, Dawson SJ, Pogrebniak K, Rueda OM, Provenzano E, Grant J, Chin SF, Tsui DW, Marass F, Gale D, Ali HR, Shah P, Contente-Cuomo T, et al. Multifocal clonal evolution characterized using circulating tumour DNA in a case of metastatic breast cancer. Nat Commun. 2015; 6:8760. https://doi.org/10.1038/ncomms9760.

4. Pentsova EI, Shah RH, Tang J, Boire A, You D, Briggs $\mathrm{S}$, Omuro A, Lin X, Fleisher M, Grommes C, Panageas KS, Meng F, Selcuklu SD, et al. Evaluating Cancer of the Central Nervous System Through Next-Generation Sequencing of Cerebrospinal Fluid. J Clin Oncol. 2016; 34:2404-15. https://doi.org/10.1200/JCO.2016.66.6487.

5. Jiang BY, Li YS, Guo WB, Zhang XC, Chen ZH, Su J, Zhong WZ, Yang XN, Yang JJ, Shao Y, Huang B, Liu YH, Zhou Q, et al. Detection of Driver and Resistance Mutations in Leptomeningeal Metastases of NSCLC by NextGeneration Sequencing of Cerebrospinal Fluid Circulating Tumor Cells. Clin Cancer Res. 2017; 23:5480-5488. https:// doi.org/10.1158/1078-0432.CCR-17-0047.

6. Novello S, Barlesi F, Califano R, Cufer T, Ekman S, Levra MG, Kerr K, Popat S, Reck M, Senan S, Simo GV, Vansteenkiste J, Peters S, et al. Metastatic non-smallcell lung cancer: ESMO Clinical Practice Guidelines for diagnosis, treatment and follow-up. Ann Oncol. 2016; 27:v1-v27. https://doi.org/10.1093/annonc/mdw326.

7. Griesinger FWE, Früh M, Gautschi O, Hile W, Hoffmann H, Huber RM, Pirker R, Pöttgen C, Pritzku leit R, Sebastian M, Thomas M, Ukena D, Wolf J, et al. Lungenkarzinom-nichtkleinzellig-nsclc. Onkopedia Leitlinien. 2017. https://doi. org/https://www.onkopedia.com/de/onkopedia/guidelines/ lungenkarzinom-nicht-kleinzellig-nsclc/@@view/html/ index.html.

8. Usmanij EA, de Geus-Oei LF, Bussink J, Oyen WJ. Update on F-18-fluoro-deoxy-glucose-PET/computed tomography in nonsmall cell lung cancer. Current Opinion in Pulmonary Medicine. 2015; 21:314-21. https://doi.org/10.1097/ mcp.0000000000000182.

9. Chuang HN, van Rossum D, Sieger D, Siam L, Klemm F, Bleckmann A, Bayerlova M, Farhat K, Scheffel J, Schulz M, Dehghani F, Stadelmann C, Hanisch UK, et al. Carcinoma cells misuse the host tissue damage response to invade the brain. Glia. 2013; 61:1331-46. https://doi. org/10.1002/glia.22518.

10. Tsai MF, Chang TH, Wu SG, Yang HY, Hsu YC, Yang PC, Shih JY. EGFR-L858R mutant enhances lung adenocarcinoma cell invasive ability and promotes malignant pleural effusion formation through activation of the CXCL12-CXCR4 pathway. Sci Rep. 2015; 5:13574. https://doi.org/10.1038/srep13574.

11. Zhao H, Guo L, Zhao H, Zhao J, Weng H, Zhao B. CXCR4 over-expression and survival in cancer: A system review and meta-analysis. Oncotarget. 2015; 6:5022-40. https:// doi.org/10.18632/oncotarget.3217.

12. Lim VY, Zehentmeier S, Fistonich C, Pereira JP. Chapter Two - A Chemoattractant-Guided Walk Through Lymphopoiesis: From Hematopoietic Stem Cells to Mature B Lymphocytes. In: Frederick WA, ed. Advances in Immunology: Academic Press). 2017; 47-88.

13. Wester HJ, Keller U, Schottelius M, Beer A, PhilippAbbrederis K, Hoffmann F, Simecek J, Gerngross C, Lassmann M, Herrmann K, Pellegata N, Rudelius M, Kessler H, et al. Disclosing the CXCR4 expression in lymphoproliferative diseases by targeted molecular imaging. Theranostics. 2015; 5:618-30. https://doi. org/10.7150/thno. 11251 .

14. Gourni E, Demmer O, Schottelius M, D'Alessandria C, Schulz S, Dijkgraaf I, Schumacher U, Schwaiger M, Kessler H, Wester HJ. PET of CXCR4 expression by a (68)Ga-labeled highly specific targeted contrast agent. J Nucl Med. 2011; 52:1803-10. https://doi.org/10.2967/ jnumed.111.098798.

15. Lapa C, Schreder M, Schirbel A, Samnick S, Kortum KM, Herrmann K, Kropf S, Einsele H, Buck AK, Wester HJ, Knop S, Luckerath K. [68Ga]Pentixafor-PET/CT for imaging of chemokine receptor CXCR4 expression in multiple myeloma - Comparison to [18F]FDG and laboratory values. Theranostics. 2017; 7:205-12. https:// doi.org/10.7150/thno. 16576 .

16. Philipp-Abbrederis K, Herrmann K, Knop S, Schottelius M, Eiber M, Luckerath K, Pietschmann E, Habringer S, Gerngross C, Franke K, Rudelius M, Schirbel A, Lapa C, et al. In vivo molecular imaging of chemokine receptor CXCR4 expression in patients with advanced multiple myeloma. EMBO Mol Med. 2015; 7:477-87. https://doi. org/10.15252/emmm.201404698.

17. Vag T, Gerngross C, Herhaus P, Eiber M, PhilippAbbrederis K, Graner FP, Ettl J, Keller U, Wester HJ, Schwaiger M. First Experience with Chemokine Receptor CXCR4-Targeted PET Imaging of Patients with Solid Cancers. Journal of Nuclear Medicine. 2016; 57:741-6. https://doi.org/10.2967/jnumed.115.161034.

18. Lapa C, Luckerath K, Rudelius M, Schmid JS, Schoene A, Schirbel A, Samnick S, Pelzer T, Buck AK, Kropf S, Wester HJ, Herrmann K. [68Ga]Pentixafor-PET/CT for imaging of chemokine receptor 4 expression in small cell lung 
cancer-initial experience. Oncotarget. 2016; 7:9288-95. https://doi.org/10.18632/oncotarget.7063.

19. Federsppiel B, Melhado IG, Duncan AM, Delaney A, Schappert K, Clark-Lewis I, Jirik FR. Molecular Cloning of the cDNA and Chromosomal Localization of the Gene for a Putative Seven-Transmembrane Segment (7-TMS) Receptor Isolated from Human Spleen. Genomics. 1993; 16:707-12. https://doi.org/http://dx.doi.org/10.1006/ geno.1993.1251.

20. Bleul CC, Farzan M, Choe H, Parolin C, Clark-Lewis I, Sodroski J, Springer TA. The lymphocyte chemoattractant SDF-1 is a ligand for LESTR/fusin and blocks HIV-1 entry. Nature. 1996; 382:829-33.

21. Ghoochani A, Schwarz MA, Yakubov E, Engelhorn T, Doerfler A, Buchfelder M, Bucala R, Savaskan NE, Eyupoglu IY. MIF-CD74 signaling impedes microglial M1 polarization and facilitates brain tumorigenesis. Oncogene. 2016; 35:6246-61. https://doi.org/10.1038/onc.2016.160.

22. Richardson PJ. CXCR4 and Glioblastoma. Anticancer Agents Med Chem. 2016; 16:59-74.

23. Zeelenberg IS, Ruuls-Van Stalle L, Roos E. The chemokine receptor CXCR4 is required for outgrowth of colon carcinoma micrometastases. Cancer Res. 2003; 63:3833-9.

24. Tripathi A, Davis JD, Staren DM, Volkman BF, Majetschak M. CXC chemokine receptor 4 signaling upon co-activation with stromal cell-derived factor-1alpha and ubiquitin. Cytokine. 2014; 65:121-5. https://doi.org/10.1016/j. cyto.2013.12.008.

25. Eby JM, Abdelkarim H, Albee LJ, Tripathi A, Gao X, Volkman BF, Gaponenko V, Majetschak M. Functional and structural consequences of chemokine (C-X-C motif) receptor 4 activation with cognate and non-cognate agonists. Molecular and Cellular Biochemistry. 2017: 1-9. https://doi.org/10.1007/s11010-017-3044-7.

26. Polzer B, Medoro G, Pasch S, Fontana F, Zorzino L, Pestka A, Andergassen U, Meier-Stiegen F, Czyz ZT, Alberter B, Treitschke S, Schamberger T, Sergio M, et al. Molecular profiling of single circulating tumor cells with diagnostic intention. EMBO Mol Med. 2014; 6:1371-86. https://doi. org/10.15252/emmm.201404033.

27. Majetschak M, Krehmeier U, Bardenheuer M, Denz C, Quintel M, Voggenreiter G, Obertacke U. Extracellular ubiquitin inhibits the TNF-alpha response to endotoxin in peripheral blood mononuclear cells and regulates endotoxin hyporesponsiveness in critical illness. Blood. 2003; 101:1882-90. https://doi.org/10.1182/blood-2002-03-0918.

28. Earle SA, El-Haddad A, Patel MB, Ruiz P, Pham SM, Majetschak M. Prolongation of skin graft survival by exogenous ubiquitin. Transplantation. 2006; 82:1544-6. https://doi.org/10.1097/01.tp.0000236057.56721.d0.

29. Tripathi A, Saini V, Marchese A, Volkman BF, Tang WJ, Majetschak M. Modulation of the CXC chemokine receptor
4 agonist activity of ubiquitin through C-terminal protein modification. Biochemistry. 2013; 52:4184-92. https://doi. org/10.1021/bi400254f.

30. Saini V, Marchese A, Majetschak M. CXC chemokine receptor 4 is a cell surface receptor for extracellular ubiquitin. J Biol Chem. 2010; 285:15566-76. https://doi. org/10.1074/jbc.M110.103408.

31. Saini V, Marchese A, Tang WJ, Majetschak M. Structural determinants of ubiquitin-CXC chemokine receptor 4 interaction. J Biol Chem. 2011; 286:44145-52. https://doi. org/10.1074/jbc.M111.298505.

32. Saini V, Staren DM, Ziarek JJ, Nashaat ZN, Campbell EM, Volkman BF, Marchese A, Majetschak M. The CXC chemokine receptor 4 ligands ubiquitin and stromal cellderived factor-1alpha function through distinct receptor interactions. J Biol Chem. 2011; 286:33466-77. https://doi. org/10.1074/jbc.M111.233742.

33. Evans AE, Tripathi A, LaPorte HM, Brueggemann LI, Singh AK, Albee LJ, Byron KL, Tarasova NI, Volkman BF, Cho TY, Gaponenko V, Majetschak M. New Insights into Mechanisms and Functions of Chemokine (C-X-C Motif) Receptor 4 Heteromerization in Vascular Smooth Muscle. Int J Mol Sci. 2016; 17. https://doi.org/10.3390/ ijms 17060971.

34. Lapa C, Kircher S, Schirbel A, Rosenwald A, Kropf S, Pelzer T, Walles T, Buck AK, Weber WA, Wester HJ, Herrmann K, Luckerath K. Targeting CXCR4 with [(68) Ga]Pentixafor: a suitable theranostic approach in pleural mesothelioma? Oncotarget. 2017; 8:96732-7. https://doi. org/10.18632/oncotarget.18235.

35. Le Rhun E, Ruda R, Devos P, Hoang-Xuan K, Brandsma D, Perez Segura P, Soffietti R, Weller M. Diagnosis and treatment patterns for patients with leptomeningeal metastasis from solid tumors across Europe. J Neurooncol. 2017; 133:419-427. https://doi.org/10.1007/ s11060-017-2452-6.

36. Clinical Lung Cancer Genome Project (CLCGP); Network Genomic Medicine (NGM). A genomics-based classification of human lung tumors. Sci Transl Med. 2013; 5:209ra153. https://doi.org/10.1126/scitranslmed.3006802.

37. Antoine T, Ott D, Ebell K, Hansen K, Henry L, Becker F, Hannus S. Homogeneous time-resolved G protein-coupled receptor-ligand binding assay based on fluorescence crosscorrelation spectroscopy. Anal Biochem. 2016; 502:24-35. https://doi.org/10.1016/j.ab.2016.02.017.

38. Martin R, Juttler S, Muller M, Wester HJ. Cationic eluate pretreatment for automated synthesis of $[(6)(8)$ Ga]CPCR4.2. Nucl Med Biol. 2014; 41:84-9. https://doi. org/10.1016/j.nucmedbio.2013.09.002. 